\title{
AN INTEGRATED FRAMEWORK FOR ANALYSING INCOME CONVERGENCE*
}

\author{
by \\ DONAL O'NEILL \\ Economics Department, NUI Maynooth \\ and \\ PHILIPPE VAN KERM \\ CEPSIINSTEAD, Differdange
}

\begin{abstract}
We develop an integrated framework for studying income convergence that incorporates traditional measures of $\beta$-convergence and $\sigma$-convergence. These concepts are formally linked by a measure of re-ranking (or leapfrogging). Our proposed measure of $\beta$-convergence allows for nonlinearities in the growth process and explicitly identifies the contribution of faster growth among low-income regions to reductions in overall inequality. To develop our framework we exploit the close links that exist between studies of income convergence and studies that examine the progressivity of the tax system. We illustrate our approach by examining both cross-country and regional income dynamics.
\end{abstract}

\section{INTRODUCTION}

The extent to which incomes have converged over time has been the focus of a large body of research in growth economics. This literature, however, has resulted in a lot of controversy, debate and confusion as to how one should measure and interpret income convergence. ${ }^{1}$ The dominant approach in the early literature is characterized by the work of Barro and Sala-i-Martin (1992). This involves regressing income growth rates on initial income to test whether poor countries grow faster than rich countries. However, several authors (Friedman, 1992; Quah, 1993) have argued that these regressions tell us little about whether income dispersion across countries has fallen: it is possible to observe poor countries growing faster than rich countries and yet for incomes to diverge. For this to happen it must be the case that the initially poorer countries overtake/leapfrog the richer countries, so that the rankings

\footnotetext{
* Manuscript received 14.6.06; final version received 6.8.07.

${ }^{\dagger}$ We would like to thank Gerry Boyle, Denis Conniffe, Olive Sweetman, Dirk Van de Gaer, two anonymous referees, and seminar participants at the Dublin Economics Workshop (Trinity College Dublin), NUI Maynooth, the Royal Economic Society meeting (Swansea) and the International Conference in Memory of Gini and Lorenz (University of Siena) for helpful comments on an earlier draft of this paper.

${ }^{1}$ Examples of recent studies of convergence include de la Fuente (2003), Phillips and Sul (2003) and de Groot et al. (2005), while Islam (2003) provides an overview of the established literature.
} 
of countries change. ${ }^{2}$ To distinguish between these different forms of convergence, Sala-i-Martin (1996a) coined the term ' $\beta$-convergence' to capture situations where 'poor economies tend to grow faster than rich ones'. In contrast a sample of countries are said to exhibit ' $\sigma$-convergence' if 'the dispersion of their real per capita GDP levels tends to decrease over time'. Friedman (1992) has argued that the real test of convergence should focus on the consistent diminution of variance among countries ( $\sigma$-convergence). Sala-i-Martin (1996a, 1996b) maintains that both concepts of convergence are interesting and should be analysed empirically.

In this paper we exploit the close links that exist between the convergence literature and the tax progression literature to develop a new framework for studying income dynamics. Our approach incorporates both the alternative measures of convergence in a coherent way. We measure $\sigma$-convergence as the change in the Gini coefficient over time and use the exact additive decomposition suggested by Jenkins and Van Kerm (2006) to express this change as the net effect of $\beta$-convergence when offset by 'leapfrogging' among countries. ${ }^{3}$

Our framework reveals more about income dynamics than studies based only on regression coefficients or correlation coefficients because we simultaneously measure three distinct facets of distributional change: $\sigma$-convergence, $\beta$-convergence and leapfrogging. ${ }^{4}$ A number of authors (e.g. Kalaitzidakis et al., 2000; Fiaschi and Lavezzi, 2003) criticize earlier work on $\beta$-convergence for failing to allow for nonlinearities in the growth process. In contrast to the traditional approach, our proposed measure of $\beta$-convergence accommodates nonlinear growth processes. Furthermore, our approach explicitly identifies the contribution of $\beta$-convergence to changes in overall inequality across countries. It also leads to a more parsimonious representation of distributional change than full-scale estimation of the joint income distribution. In addition, our approach can easily incorporate varying degrees of inequality aversion when measuring dispersion.

${ }^{2}$ For a recent example of a theoretical growth model with leapfrogging/overtaking, see Sugimoto (2006).

${ }^{3}$ Wodon and Yitzhaki (2005) look at growth and convergence using an alternative Gini-based decomposition. Their approach differs from ours in that they adopt a specific social welfare function, which they decompose into growth, inequality and mobility components. Our focus is on the decomposition of changes in inequality.

${ }^{4}$ Hart (1995) shows that when income growth can be written as $y_{i, t+1}-y_{i, t}=\beta y_{i, t}+\varepsilon_{i, t+1}$, the ratio of the variance of incomes can be written as

$$
\frac{\operatorname{Var}\left(y_{i, t+1}\right)}{\operatorname{Var}\left(y_{i, t}\right)}=\frac{(\beta+1)^{2}}{\rho^{2}}
$$

where $\rho$ is the correlation of incomes in both periods. $\sigma$-Convergence requires that $\beta+1<\rho$ or equivalently $\beta<\rho-1$. Since $\rho \leq 1$, this expression shows that $\beta$-convergence $(\beta<0)$ is a necessary but not a sufficient condition for $\sigma$-convergence. While $\rho$ can be thought of as one particular index of mobility there is no direct relationship between $\rho$ and the concept of leapfrogging. Our decomposition, on the other hand, provides a non-parametric framework in which the individual contributions of $\beta$-convergence and leapfrogging to changes in overall inequality can be explicitly identified and measured. 


\section{Decomposing Inequality Change}

Previous studies of cross-country or regional income dispersion have tended to use either the coefficient of variation of GDP (e.g. Friedman, 1992) or the standard deviation of log GDP (e.g. Sala-i-Martin, 1996a) to summarize income inequality. A number of alternative indices are available however. ${ }^{5}$ In this paper, we follow Wodon and Yitzhaki (2005) and adopt the Gini index as our measure of inequality. ${ }^{6}$ The Gini index is used extensively in the public economics literature when dealing with taxation and income redistribution across individuals (see Lambert, 1993). It is related to the Lorenz curve of the income distribution, which can be constructed by lining individuals up in ascending order of incomes and observing them as they parade by. As they pass by, each individual hands over their income. Let $p$ denote the proportion of people who have passed by at a given time and let $L(p)$ denote the proportion of total income that has been handed in at that time. The Lorenz curve is simply the graph of $L(p)$ against $p .^{7}$

The Gini coefficient measures twice the area between the 45-degree line (the Lorenz curve with complete equality) and the Lorenz curve of the actual income distribution:

$$
G=2 \int_{0}^{1}[p-L(p)] \mathrm{d} p
$$

or equivalently

$$
G=1-2 \int_{a}^{b}[1-F(x)] \frac{x}{\mu} f(x) \mathrm{d} x
$$

where $a$ and $b$ are the lower and upper bounds of income, $F$ and $f$ are, respectively, the cumulative distribution and the density function of incomes, and $\mu$ is mean income (Lambert, 1993). The second formulation makes it clear that the Gini coefficient is equal to one minus twice a weighted average of mean-normalized incomes $(x / \mu)$. Crucially, the weights, given by $1-F(x)$, are determined by the relative rank of agents' incomes in the distribution. The lowest income receives a weight of one; weights decrease as we move to the highest income, which receives a weight of zero. As will become clear, the ability to identify both a rank component and a relative income component in the construction of the Gini coefficient plays a key role in our analysis.

When considering the bivariate distribution of incomes at two time periods, 1 and 2, an analogous concept can be defined as twice the area

\footnotetext{
${ }^{5}$ See, for example, Jenkins (1991) or Cowell (2000) for surveys.

${ }^{6} \mathrm{An}$ important advantage of the Gini index over measures commonly used in the convergence literature is that it satisfies the 'principle of transfers' according to which inequality is necessarily increased by a transfer of income from a poorer agent to a richer agent.

${ }^{7}$ See Gastwirth (1971) for a formal definition.
} 
between the 45-degree line and the concentration curve. To construct the concentration curve, line up individuals in ascending order of period 1 incomes as before, but imagine that, as they pass by, each individual hands over their second-period income. The concentration curve plots $p$, the proportion of people who have passed by, against $C(p)$, the proportion of second-period income that has been handed in. The associated index is called the concentration coefficient, which we denote as $C_{1}^{2}$, and is defined as

$$
C_{1}^{2}=2 \int_{0}^{1}[p-C(p)] \mathrm{d} p
$$

Integrating this expression by parts, $C_{1}^{2}$ can be re-expressed as

$$
C_{1}^{2}=1-2 \int_{a}^{b} \int_{a}^{b}\left[1-F^{1}(x)\right] \frac{y}{\mu^{2}} h(x, y) \mathrm{d} x \mathrm{~d} y
$$

where $F^{1}(x)$ is the cumulative distribution function of period 1 incomes, $\mu^{2}$ is the mean period 2 incomes and $h$ is the bivariate density function of incomes at periods 1 and 2. Again, it becomes evident that the concentration coefficient is determined by a weighted average of period 2 mean-normalized incomes, where the weights are determined by period 1 relative ranks $\left(1-F^{1}(x)\right)$.

Using these two measures, Jenkins and Van Kerm (2006) have shown that the change in the Gini coefficient between period 1 and period 2 can be meaningfully decomposed as

$$
\Delta G=G^{2}-G^{1}=\left(G^{2}-C_{1}^{2}\right)-\left(G^{1}-C_{1}^{2}\right)=R-B C
$$

where $G^{t}$ is the Gini coefficient of period $t$ incomes. When the units of analysis are countries or regions, the left-hand side of (3) provides a direct measure of $\sigma$-convergence; $\Delta G>0$ corresponds to rising inequality or income divergence and $\Delta G<0$ reflects falling income inequality or income convergence. Equation (3) decomposes this change into two parts, $R$ and $B C$. The second term, $B C$, is a weighted average of (mean-normalized) GDP growth in each region where the weights are given by the regions' ranks in the initial distribution of incomes. ${ }^{8}$ In the tax literature, where pre-tax and post-tax incomes are compared, this term is referred to as the Reynolds-Smolensky index of vertical equity that is proportional to the Kakwani measure of tax progressivity (Kakwani, 1977). $B C$ equals zero if growth rates are equal in all regions. $B C$ is positive (inequality falls) if growth tends to be higher in poorer regions; in keeping with the tax literature we call this a progressive growth process. The

${ }^{8}$ To see this, write the Gini coefficient at period 1 as

$$
G^{1}=1-2 \int_{a}^{b} \int_{a}^{b}\left[1-F^{1}(x)\right] \frac{x}{\mu^{1}} h(x, y) \mathrm{d} x \mathrm{~d} y
$$

and compare it with expression (2) for the concentration index. 
greater the concentration of GDP growth among low-income regions, the larger $B C$ becomes and hence the larger the reduction in inequality. In contrast, $B C$ is negative if growth tends to be higher among richer regions, a factor leading to an increase in inequality. Since $B C$ captures the extent to which faster growth among poor regions reduces inequality it has a clear interpretation as a distributive measure of $\beta$-convergence.

As argued by Friedman (1992) the effect of $\beta$-convergence on inequality is mitigated by the re-ranking of countries, which occurs if initially poor regions overtake richer regions. Once a poor region catches up with a richer region, further increases in the GDP of the initially poor region will push inequality upward again (with a reversal of ranks). $R$, in our decomposition, measures this effect. In calculating $R$ only incomes from the final distribution of income are used. However, the positioning of a country or region in the income parade used to construct the aggregate measure of inequality is allowed to change. When calculating $G^{2}$, countries are ordered and weighted according to period 2 ranking, while the calculation of $C_{1}^{2}$ uses the period 1 ranking. ${ }^{9}$ The $R$ term, which can be seen as the residual difference between $B C$ and $\Delta G$, quantifies the offsetting effect of re-ranking (positional mobility) on the inequality reduction. This captures the fact that $\beta$-convergence need not necessarily translate into lower overall inequality if poor countries leapfrog richer countries and, in this sense, quantifies the concerns expressed by Friedman (1992).

Viewing the change in inequality in this way allows us to identify easily the relative contribution of both re-ranking and progressive growth ( $\beta$-convergence) to the overall change in inequality ( $\sigma$-convergence). In addition, our specification is quite general. Equation (3) is an accounting identity and therefore holds without any additional assumptions; there is nothing in our framework that requires the underlying growth process to be constant across countries, linear in income or monotonic as required when $\beta$-convergence is estimated in a linear regression framework. Our decomposition therefore provides a non-parametric framework that identifies the key components of the convergence process. ${ }^{10}$

Figures 1-5 provide illustrative examples, in a two-country setting, of the range of income dynamics that are easily captured by equation (3). Figures 1 and 2 both illustrate situations where $\beta$-convergence and $\sigma$-convergence coexist. In the first situation there is no leapfrogging. In our approach the $\sigma$-convergence is captured by a fall in the Gini coefficient. All of

${ }^{9}$ Write the Gini coefficient at period 2 as

$$
G^{2}=1-2 \int_{a}^{b} \int_{a}^{b}\left[1-F^{2}(y)\right] \frac{y}{\mu^{2}} h(x, y) \mathrm{d} x \mathrm{~d} y
$$

and compare it with equation (2).

${ }^{10}$ The decomposition presented here can be easily extended to situations where the generalized Gini coefficient is used to measure convergence. For a discussion of the generalized Gini coefficient, see Donaldson and Weymark (1980) and Yitzhaki (1983). 


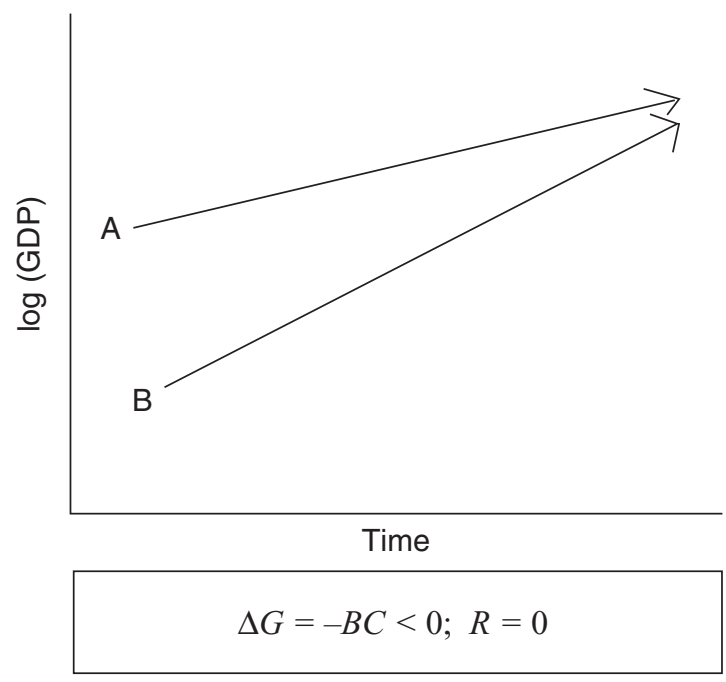

FIG. $1 \beta$-Convergence, $\sigma$-Convergence, No Leapfrogging

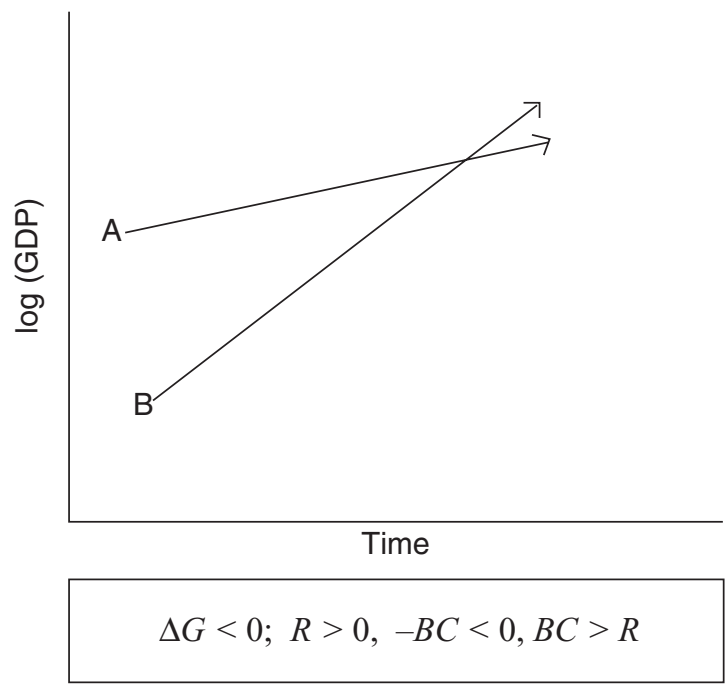

FIG. $2 \beta$-Convergence, $\sigma$-Convergence and Leapfrogging

this reduction can be attributed to the progressivity of income growth, so that $\Delta G=-B C$. The absence of re-ranking is reflected in $R=0$. In the second example incomes converge despite re-ranking. This would be captured in our framework by values of $B C$ and $R$ such that $-B C<0, R>0$ and $B C>R$, highlighting the dominant role of $\beta$-convergence in reducing inequality. 


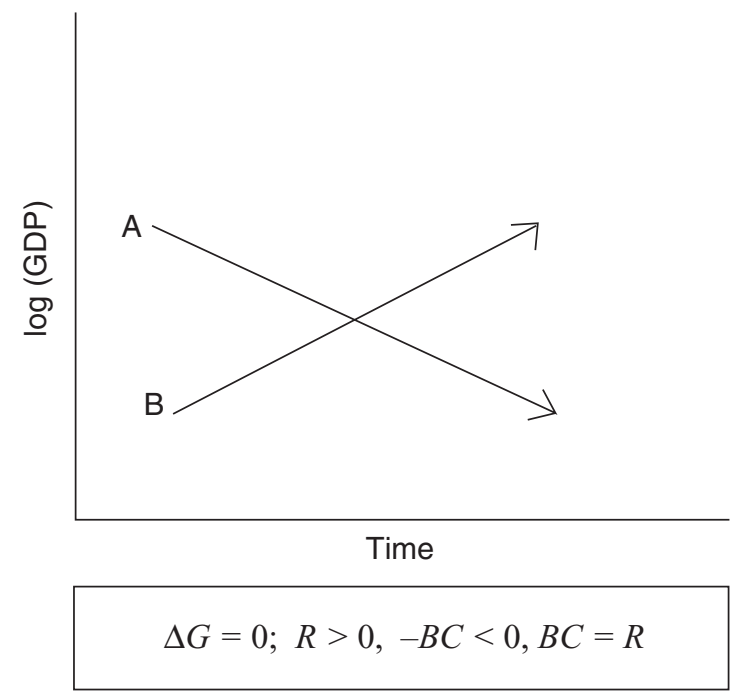

FIG. $3 \beta$-Convergence, No $\sigma$-Convergence, Leapfrogging

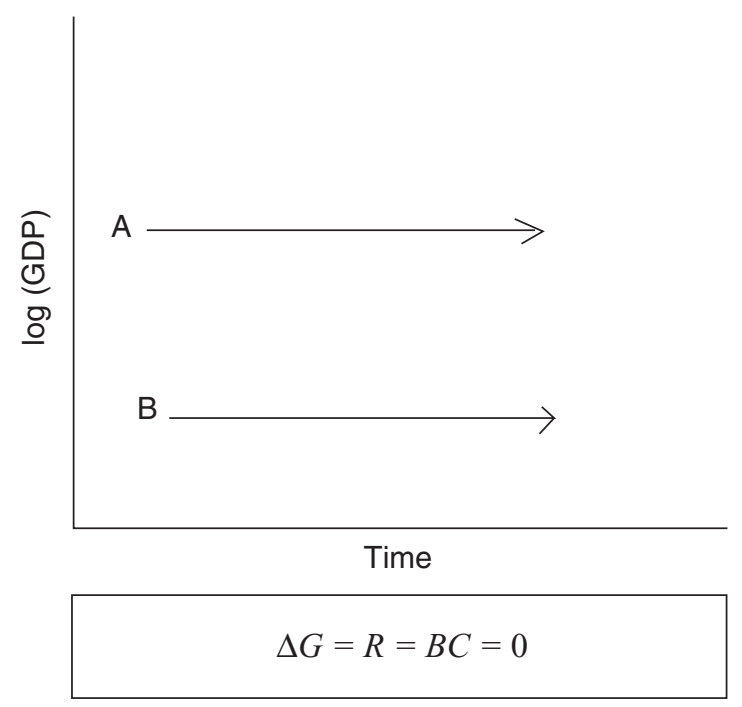

FIG. 4 No $\beta$-Convergence, No $\sigma$-Convergence, No Leapfrogging

Figures 3 and 4 both illustrate situations where there is no $\sigma$-convergence $(\Delta G=0)$. In Fig. 3, however, poor countries grow faster than rich countries so that we have substantial $\beta$-convergence. This is masked in the overall inequality figure by the complete re-ranking of the two countries. 


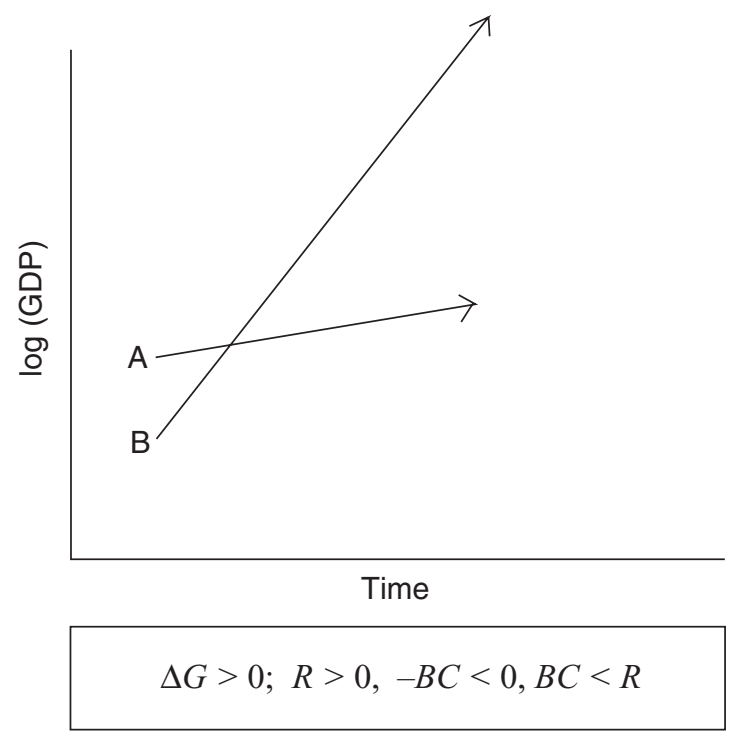

FIG. $5 \beta$-Convergence, $\sigma$-Divergence, Leapfrogging

Our approach will identify the contribution of $\beta$-convergence to reduced inequality in these data but this will be entirely offset by the contribution of the leapfrogging component, so that $B C=R>0$. Not only does our framework identify the tendency of poor countries to grow faster but it also simultaneously quantifies the extent to which this is offset by re-ranking in the data. In contrast to Fig. 3, Fig. 4 illustrates another situation in which there is no $\sigma$-convergence. However, this case differs from that in Fig. 3 in that the new environment is completely static. Again $\Delta G=0$, but in this case our decomposition would result in $B C=R=0$. Our framework would identify the growth profile in Fig. 4 as one without either $\beta$-convergence or leapfrogging.

There are theoretical reasons as to why one might wish to distinguish between the examples in Figs 3 and 4. A number of authors, e.g. Barro and Sala-i-Martin (1992) and Islam (2003), have shown that income per capita in a stochastic Solow growth model converges to a stationary distribution with a constant (non-zero) variance, which depends on the variance of the stochastic component of the model. As noted by de la Fuente (1997), this implies that 'in the long-run we should observe a fluid distribution in which relative positions of the different countries change rapidly' (p. 36). Therefore, the steady-state income dynamics should correspond to Fig. 3 rather than Fig. 4. Our framework provides a straightforward way of identifying such outcomes. 
Finally, Fig. 5 illustrates a situation where we have $\beta$-convergence and $\sigma$-divergence. Here the effect of the leapfrogging more than offsets the reduction in inequality arising from $\beta$-convergence. In this case we have $\Delta G>0$, $-B C<0, R>0$ and $R>B C$.

These examples also help to clarify an important point. Sala-i-Martin (1996b) begins his paper by defining $\beta$-convergence in the traditional way, noting that 'there is $\beta$-convergence if poor economies tend to grow faster than rich ones'. However, later in the paper he suggests that $\beta$-convergence studies the mobility of income within the same distribution. As a result, some researchers have drawn parallels between $\beta$-convergence and measures of rank mobility, defining indices of rank concordance as direct measures of $\beta$-convergence (Boyle and McCarthy, 1997). Clearly for a distribution to exhibit $\beta$-convergence, without $\sigma$-convergence, it must be the case that countries are changing ranks (Fig. 3). However, as Fig. 1 shows, it is possible to have $\beta$-convergence without any positional mobility; it is also possible to have rank mobility without $\beta$-convergence. $\beta$-Convergence simply requires poor countries to grow faster than rich countries, irrespective of whether or not there is leapfrogging. Both the Barro-regression approach and our approach would indicate a strong role for $\beta$-convergence for the process illustrated in Fig. 1; measures based on rank correlations would not. While the issue of positional mobility is interesting, it is captured by our measure $R$; this, in turn, measures the offsetting effect of re-ranking/leapfrogging on $\sigma$-convergence and not $\beta$-convergence.

Quah (1996) uses diagrams similar to these to argue that neither $\beta$-convergence nor $\sigma$-convergence, alone, delivers a convincing description of the dynamics of evolving distributions. Quah (1996) proposes an alternative procedure based on estimation of stochastic kernels; ${ }^{11}$ our analysis builds on established work in public economics to offer a coherent complement to the kernel density approach. Our framework integrates three important features of the convergence process, $\sigma$-convergence, $\beta$-convergence and leapfrogging, in a way that is easy to implement and interpret. The parsimony evident in our decomposition comes at a cost; while our analytical framework accommodates nonlinear growth processes, it cannot identify whether or not these nonlinearities lead to the emergence of convergence clubs. ${ }^{12} \mathrm{We}$ recognize that the emergence of convergence clubs has an important role to play in studying income dynamics and we briefly document the existence of convergence clubs in our data summary section. However, we believe that the provision of a rich, though partial, non-parametric summary of the mobility process, which links competing measures of convergence at a fraction of the computational cost of alternative approaches, is a useful contribution to the literature on income convergence. Quantifying the polarization of the income

\footnotetext{
${ }^{11}$ For a related discussion, see Maasoumi et al. (2007).

${ }^{12}$ Canova (2004) discusses the identification of convergence clubs in detail. 
distribution across countries around convergence clubs is conceptually distinct from quantifying overall convergence and requires complementary, but different, tools. ${ }^{13}$

\section{Data And Results}

\subsection{Convergence across Countries}

In this section, we illustrate our approach with an analysis of income convergence between 1960 and 2000, using data from the latest version of the Penn World Tables. ${ }^{14}$ The Penn World Tables provide price-adjusted income measures for a large sample of countries for the years 1950-2000 and have been used extensively in previous studies of convergence. In this paper, we use data for a sample of 98 countries that provide complete data over the period 1960-2000. We also look at income dynamics for a restricted set of 25 Organization for Economic Cooperation and Development (OECD) countries. Income is measured as real per capita gross domestic product in 1996 international prices. ${ }^{15}$ The countries used in our analysis are listed in Table 1.

Figures 6 and 7 provide a graphical summary of the evolution of income inequality over the sample period. Figure 6 summarizes the data for the OECD sample, while Fig. 7 provides the results for the full sample. We focus first on the OECD countries. For the purposes of drawing these graphs incomes are expressed relative to the overall mean for that year; values above one correspond to high-income countries and values below one represent low-income countries. The north east and south west quadrants of Fig. 6 are the empirical quantile functions of (mean-normalized) income; they plot the relationship between income and rank in each of the two years. As shown in Section 2, the Gini coefficient is a weighted integral of the area under these curves with weights decreasing as we move from poor to rich countries.

The north west quadrant maps the relationship between incomes in each of the marginal distributions. Income in 1960 ( $x$-coordinate) is plotted against income in 2000 ( $y$-coordinate). The 45-degree line corresponds to a situation of proportional income growth. We see that among OECD countries, those with low initial incomes have seen their incomes rise fastest over this period. Our progressivity measure, $B C$, is equivalent to a weighted average of the individual distance of each observation from the 45-degree line, with greater weights given to countries with lower initial incomes.

\footnotetext{
${ }^{13}$ Esteban and Ray (1994) and Esteban et al. (2004) discuss this distinction in detail in the context of personal income distribution analysis.

${ }^{14}$ Alan Heston, Robert Summers and Bettina Aten, Penn World Table Version 6.1, Center for International Comparisons at the University of Pennsylvania (CICUP), October 2002.

${ }^{15}$ For the results presented in this paper all countries are weighted equally, although our procedure can easily accommodate individual country weights. For a discussion of the impact of using population weights when analysing cross-country income inequality see Jones (1997). 
TABLE 1

Full SAmple of 98 Countries InCluded in the ANalysis

\begin{tabular}{|c|c|c|c|c|}
\hline Argentina & Costa Rica & India & Malawi & Sweden $^{\mathrm{a}}$ \\
\hline Australia ${ }^{\mathrm{a}}$ & Denmark $^{\mathrm{a}}$ & Ireland $^{\mathrm{a}}$ & Malaysia & Switzerland ${ }^{a}$ \\
\hline Austria $^{\mathrm{a}}$ & Dominican Republic & Iran & Niger & Seychelles \\
\hline Burundi & Algeria & Iceland $^{\mathrm{a}}$ & Nigeria & Syria \\
\hline Belgium $^{\mathrm{a}}$ & Ecuador & Israel & Nicaragua & Chad \\
\hline Benin & Egypt & Italy ${ }^{a}$ & Netherlands ${ }^{\mathrm{a}}$ & Togo \\
\hline Burkina Faso & Ethiopia & Jamaica & Norway $^{\mathrm{a}}$ & Thailand \\
\hline Bangladesh & Finland $^{\mathrm{a}}$ & Jordan & Nepal & $\begin{array}{l}\text { Trinidad and } \\
\text { Tobago }\end{array}$ \\
\hline Bolivia & France $^{\mathrm{a}}$ & Japan $^{\mathrm{a}}$ & New Zealand ${ }^{a}$ & Turkey $^{a}$ \\
\hline Brazil & Gabon & Kenya & Pakistan & Tanzania \\
\hline Barbados & Ghana & Korea $^{a}$ & Panama & United Kingdom ${ }^{\mathrm{a}}$ \\
\hline Canada $^{\mathrm{a}}$ & Guinea & Sri Lanka & Peru & Uganda \\
\hline Chile & Gambia & Lesotho & Philippines & Uruguay \\
\hline China & Guinea-Bissau & Luxembourga & Portugal $^{\mathrm{a}}$ & $\mathrm{USA}^{\mathrm{a}}$ \\
\hline Cote d'Ivoire & Equatorial Guinea & Morocco & Paraguay & Venezuela \\
\hline Cameroon & Greece $^{\mathrm{a}}$ & Madagascar & Romania & South Africa \\
\hline Republic of Congo & Guatemala & Mexico $^{\mathrm{a}}$ & Rwanda & Zambia \\
\hline Colombia & Hong Kong & Mali & Senegal & Zimbabwe \\
\hline Comoros & Honduras & Mozambique & Spain $^{\mathrm{a}}$ & \\
\hline Cape Verde & Indonesia & Mauritius & El Salvador & \\
\hline
\end{tabular}

${ }^{a}$ Members of the OECD sample. Of the 30 countries currently listed as members of the OECD, the Czech Republic, Slovakia, Poland, Hungary and Germany did not have consistent data for the period 1960-2000.

The south east quadrant captures the extent of leapfrogging. Deviations from the 45-degree line in this quadrant show the extent of re-ranking; countries above the 45-degree line have increased their rank over time and vice versa. The results show that almost every country changed rank over this period; countries such as Ireland, Japan and Norway moved up the distribution; countries such as Sweden, New Zealand and Britain moved down. There is no immediate mapping from this graphical presentation of leapfrogging to our summary measure $R$; the easiest way to visualize the impact of leapfrogging on relative incomes is to look at the nature and composition of income clusters in both years. Looking at the north west quadrant for 1960 (along the horizontal axis) we can identify approximately three clusters of countries: a low-income cluster consisting of Korea, Turkey, Mexico, Greece, Portugal, Spain, Japan and Ireland; a high-income cluster involving Luxembourg, USA, Switzerland and New Zealand; and a cluster of middle-income countries made up of the remaining OECD members. Switching axis to look at 2000, there still appears to be a low-income, middle-income and high-income cluster; furthermore, our graph allows us to look at compositional changes within and between these clusters. We notice that Switzerland and New Zealand have fallen out of the high-income group, with Switzerland moving down into the middle group and New Zealand moving towards the lowincome cluster; the big movers out of the low-income group were Ireland and Japan, who have now joined the middle-income countries. 


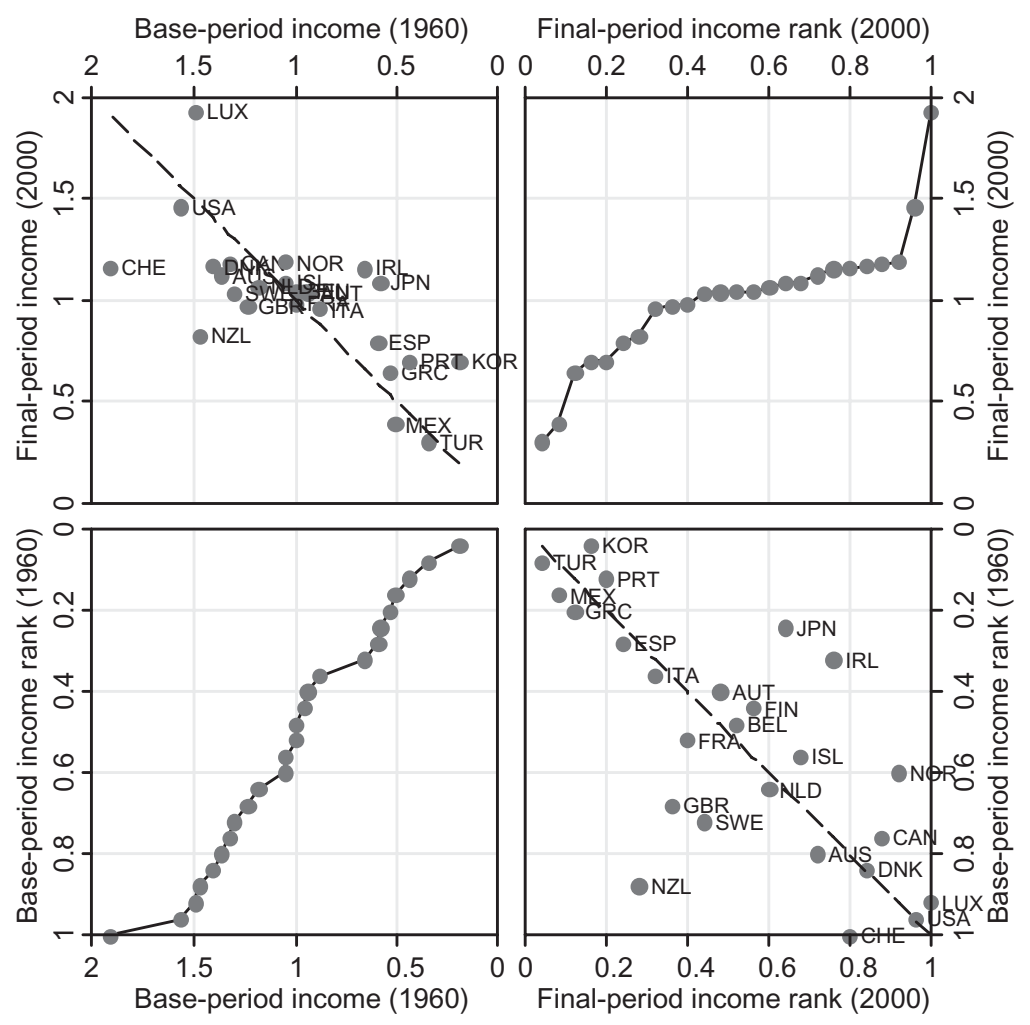

FIG. 6 Graphical Summary of Evolution of Income Inequality among OECD Countries 1960-2000

Figure 7 provides the same analysis for the full sample of 98 countries. The growth in relative incomes for this sample tends to be concentrated in the middle of the distribution, with relative incomes at the very top of the distribution falling. Although identifying individual countries becomes more difficult, it is apparent that much of the leapfrogging that occurred over this time period resulted in countries changing positions within groups; relatively few countries changed groups.

We can use the decomposition presented in equation (3) to look at these changes more formally. Table 2 reports the Gini coefficient for the full data and for the restricted set of OECD countries, at 10-year intervals, for the period 1960-2000. Breaking the sample period into 10-year intervals accommodates inter-temporal heterogeneity in the growth process. For comparison, we also report the standard deviation of log income. Looking at the OECD countries we see that the overall trend is similar for the two measures and indicates a substantial reduction of income dispersion over the period 


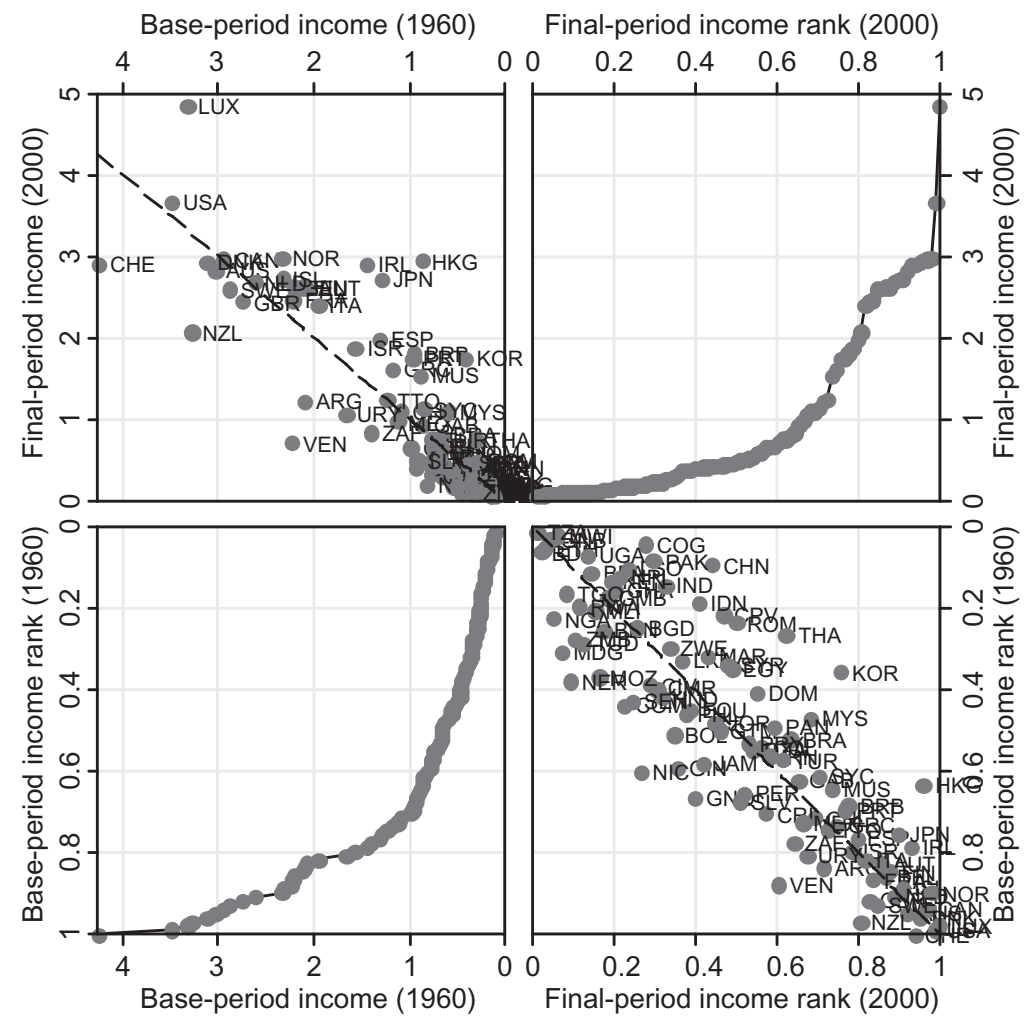

FIG. 7 Graphical Summary of Evolution of Income Inequality among All Countries $1960-2000$

TABLE 2

Relative Trends in InCome Inequality

\begin{tabular}{lccccc}
\hline & \multicolumn{2}{c}{25 OECD countries } & & \multicolumn{2}{c}{ Full sample $(N=98)$} \\
\cline { 2 - 3 } \cline { 5 - 6 } Time period & Gini & $\sigma_{\ln (\mathrm{GDP})}$ & & Gini & $\sigma_{\ln (\mathrm{GDP})}$ \\
\hline 1960 & 0.253 & 0.547 & & 0.483 & 0.928 \\
1970 & 0.205 & 0.472 & & 0.503 & 1.02 \\
1980 & 0.174 & 0.418 & & 0.510 & 1.08 \\
1990 & 0.169 & 0.385 & & 0.538 & 1.14 \\
2000 & 0.171 & 0.385 & & 0.553 & 1.22 \\
\hline
\end{tabular}

1960-2000. The majority of this reduction took place between 1960 and 1980; convergence slowed down significantly after this period. ${ }^{16}$ Results for the world as a whole confirm what has been established in many previous studies: incomes diverged substantially over the period.

${ }^{16}$ This slowdown in convergence among developed countries was discussed in O'Neill (1996). 
TABLE 3

Income Convergence Dynamics For 25 OECD Countries: 1960-2000 (STANDARd ERrors in PARENTHESES)

\begin{tabular}{lcccc}
\hline Time period & $\sigma$-Convergence $\Delta G$ & $\beta$-Convergence $-B C$ & Re-ranking $R$ & Barro regression $\beta$ \\
\hline $1960-2000$ & $-0.083(0.034)$ & $-0.116(0.035)$ & $0.033(0.011)$ & $-0.012(0.003)$ \\
$1960-1970$ & $-0.048(0.013)$ & $-0.056(0.015)$ & $0.008(0.004)$ & $-0.016(0.005)$ \\
$1970-1980$ & $-0.031(0.010)$ & $-0.045(0.010)$ & $0.014(0.007)$ & $-0.013(0.004)$ \\
$1980-1990$ & $-0.005(0.014)$ & $-0.013(0.013)$ & $0.008(0.004)$ & $-0.012(0.006)$ \\
$1990-2000$ & $0.002(0.019)$ & $-0.009(0.022)$ & $0.011(0.006)$ & $-0.005(0.006)$ \\
\hline
\end{tabular}

TABLE 4

Income Convergence Dynamics for the Full Sample of 98 Countries: 1960-2000 (STANDARd ERrors in PARENTHESES)

\begin{tabular}{lcccc}
\hline Time period & $\sigma$-Convergence $\Delta G$ & $\beta$-Convergence $-B C$ & Re-ranking $R$ & Barro regression $\beta$ \\
\hline $1960-2000$ & $0.07(0.020)$ & $0.017(0.020)$ & $0.053(0.013)$ & $0.004(0.002)$ \\
$1960-1970$ & $0.02(0.008)$ & $0.012(0.008)$ & $0.008(0.002)$ & $0.006(0.002)$ \\
$1970-1980$ & $0.007(0.008)$ & $-0.003(0.008)$ & $0.010(0.002)$ & $0.003(0.002)$ \\
$1980-1990$ & $0.028(0.007)$ & $0.020(0.007)$ & $0.008(0.002)$ & $0.003(0.002)$ \\
$1990-2000$ & $0.015(0.008)$ & $0.010(0.008)$ & $0.005(0.001)$ & $0.007(0.002)$ \\
\hline
\end{tabular}

The results in Tables 3 and 4 decompose these changes in income inequality using the framework outlined in Section 2. The rows of the tables refer to different time periods, while the columns refer to the various components of the convergence process; the second column shows the change in the Gini coefficient and measures $\sigma$-convergence; the third and fourth columns present the respective contributions of progressive income growth $(-B C)$ and re-ranking/leapfrogging $(R)$ to the change in overall inequality. ${ }^{17}$ The final column reports the traditional measure of $\beta$-convergence derived from a Barro regression.

Looking at the results in Table 3 we see that leapfrogging plays a minor role in the cross-country income dynamics of OECD countries; re-ranking did little to offset the reduction in inequality induced by $\beta$-convergence between 1960 and $1980 .{ }^{18}$ Furthermore, we see that the stable income distribution observed over the last 10 years reflects a static distribution; neither leapfrogging nor $\beta$-convergence contributed anything to changing income dispersion across countries over this period. The last column presents our estimates of the traditional measure of $\beta$-convergence from growth regres-

\footnotetext{
${ }^{17}$ The standard errors on the decomposition terms were constructed using a classical paired bootstrap procedure with 1000 replications. At each iteration the unit of resampling was the vector containing both initial and final period incomes.

${ }^{18}$ Using measures of rank correlations, Boyle and McCarthy (1997) also concluded that 'positional mobility' was relatively unimportant over this time. However, our approach differs in two ways: first, we can determine precisely the contribution of this component to changes in overall inequality; second, we do not equate positional mobility with $\beta$-convergence.
} 
sions; the results are reported so that a negative $\beta$ indicates convergence. For the most part, these results are consistent with our earlier analysis. The early periods are characterized by significant $\beta$-convergence; this is absent in the later years. However, it is worthwhile making two observations. First, we observe both leapfrogging and values of $|\beta|<1$ in every period under consideration. Therefore, we need to be careful when interpreting claims that $|\beta|<1$ rules out leapfrogging; this applies only to 'deterministic' leapfrogging, where poor economies are systematically predicted to get ahead of rich economies. A value of $|\beta|<1$ says nothing about positional mobility in general. ${ }^{19}$ Second, it is interesting to compare the full period from 1960 to 2000 with that from 1980 to 1990 . For both periods the estimated $\beta$ coefficients from the growth equations are almost identical. However, when we look at columns 2 and 3 we see that, for the two periods in question, the dynamics underlying the income distribution were substantially different. For the overall period progressive income growth had a significant equalizing effect. In the later period, however, total income inequality did not change. Furthermore, our decomposition shows that neither leapfrogging nor $\beta$-convergence had a significant impact on inequality over this period. This is an illustration of Friedman's concern that relying on Barro regressions may mask important differences in income dynamics. Therefore, even if we accept the tendency for Barro regressions to return a rate of convergence of 2 per cent over a wide range of different examples, our framework shows how the equalizing effects of these processes may differ substantially. ${ }^{20}$

Table 4 presents the results for the full sample. In contrast to the OECD sample we find little evidence of $\beta$-convergence. For almost every period considered the regressive nature of income growth and leapfrogging combined to increase income dispersion. When the full 40-year period is considered we see that leapfrogging was the dominant force driving income dynamics; this at a time when growth was regressive. The combined results in Tables 3 and 4 quantify Maasoumi et al.'s (2007) assertion that 'there is much "churning," or "exchange mobility," and no convergence within the non-OECDs and a tangible convergence and "growth mobility" within the OECDs'. Although the results in Table 4 are, for the most part, consistent with the traditional Barro-regression results, we again see examples of how growth processes with similar coefficients from the Barro regression

\footnotetext{
${ }^{19}$ It is possible to extend our decomposition to incorporate systematic and stochastic components and details of such an extension are given in the Appendix. Alternative discussions are given in Lerman and Yitzhaki (1995), Duclos et al. (2003) and Urban and Lambert (2005). Distinguishing between systematic and stochastic components would require a reliable estimator of the mean of final-period income conditional on initial income. This is likely to prove difficult given our sample sizes. As a result we focus on the simpler decomposition given by equation (3).

${ }^{20}$ Dardanoni and Lambert (2002) make a related point in a different context, when noting that tax schedules with similar measures of structural progression can differ substantially in their effective redistribution.
} 
(1970-80 and 1980-90) may be associated with different reductions in inequality. These differences are captured by our distribution-based measure of $\beta$-convergence.

\subsection{Convergence across Regions}

In this section we use our framework to study regional income dynamics with data taken from Barro and Sala-i-Martin (1995). These data were used by Sala-i-Martin (1996b) to study regional cohesion. In particular, we focus on the regions of the USA and Japan. The dates for which the analysis is conducted depend on data availability and differ across data sets. The data for the USA refer to real annual personal income per capita for each of the 48 contiguous states from 1900 to 1990. The Japanese data measure real per capita income between 1955 and 1990 for the 47 prefectures, as collected by the Economic Planning Agency of Japan. More details on these data, including summary statistics and maps illustrating the regions under consideration, are available in Barro and Sala-i-Martin (1995).

Tables 5 and 6 show the results of the decomposition for the US states and Japanese regions, respectively. As before, column 3 reports our modified distribution-based measure of $\beta$-convergence $(-B C)$, column 4 shows the contribution of leapfrogging $(R)$ and column 5 is the traditional $\beta$ coefficient from a Barro regression. For both regional data sets we see a dominant role for $\beta$-convergence in reducing income inequality across regions. This has been offset to some extent by the effects of leapfrogging but in both cases the progressivity effect is about four times the size of the contribution of leapfrogging. This captures growth processes where substantial $\beta$-convergence leads directly to $\sigma$-convergence. Interestingly, our results suggest that convergence was larger in the US sample (as measured by both $\Delta G$ and $B C$ ), but that does not appear in the Barro regressions.

TABLE 5

Income Convergence Dynamics for 48 US States: 1900-90 (STANDARD ERRORS IN PARENTHESES)

\begin{tabular}{lcccc}
\hline Time period & $\sigma$-Convergence $\Delta G$ & $\beta$-Convergence $-B C$ & Re-ranking $R$ & Barro regression $\beta$ \\
\hline $1900-1990$ & $-0.141(0.023)$ & $-0.187(0.026)$ & $0.047(0.011)$ & $-0.009(0.001)$ \\
\hline
\end{tabular}

TABLE 6

Income Convergence Dynamics for 47 Japanese Prefectures: 1955-90 (Standard Errors IN PARENTHESES)

\begin{tabular}{lcccc} 
Time period & $\sigma$-Convergence $\Delta G$ & $\beta$-Convergence $-B C$ & Re-ranking $R$ & Barro regression $\beta$ \\
\hline $1955-1990$ & $-0.047(0.011)$ & $-0.069(0.010)$ & $0.022(0.006)$ & $-0.011(0.001)$ \\
\hline
\end{tabular}




\section{Conclusion}

The results presented in this paper are consistent with earlier studies of inequality and growth. However, we believe that the approach adopted represents a useful development in the analysis of cross-country and regional income dynamics. The techniques we use allow us to 'marry' the approaches advocated by Friedman and Quah with those suggested by Barro and Salai-Martin. In doing so we develop an integrated framework involving concepts that, up to now, have often been viewed as competitors in the analysis of income dynamics. We adapt concepts originally developed to study the progressivity of the tax system and use the new approach to study cross-country and regional income dynamics. Our framework allows us to evaluate and understand the connections between the various sources of convergence discussed in the literature, while at the same time accommodating quite general specifications of the underlying growth process.

Our analysis illustrates how studies relying on the coefficient from a linear regression model to capture $\beta$-convergence may hide important differences in the income dynamics. Our preferred measure of $\beta$-convergence captures the extent to which faster income growth among low-income countries reduces income dispersion. Our results show significant reductions in inequality among the OECD, US states and Japanese prefectures because of faster growth among low-income regions; for these samples the occurrence of leapfrogging did little to offset the reduction in overall dispersion induced by $\beta$-convergence.

In contrast to recently developed approaches based on the estimation of full-scale conditional density functions, our approach quantifies key features of (global) convergence in just three summary parameters, which are easy to estimate. This parsimony, however, comes at cost in that our approach does not readily identify or quantify other features of distributional changes such as polarization around (local) convergence clubs. It may also be useful to extend our approach to allow further explanation of the processes driving the observed convergence patterns. Further decomposition of our measures into systematic and stochastic components, as outlined in the Appendix, offers a potential starting point. We believe that developments in this direction may be a useful avenue for future research.

\section{APPENDiX}

\section{Measuring Convergence with Systematic and Stochastic Components}

When analysing income dynamics it is sometimes useful to distinguish between 'systematic' and 'stochastic' income growth. The systematic component of final income is defined as the expected final-period income conditional on initial income. However, a country's observed final-period income may deviate from their expected income and these deviations represent the stochastic component of final income. Identifying the 
contributions of 'systematic' and 'stochastic' income growth to the overall convergence and re-ranking requires an estimate of the conditional mean income. An approach commonly used in the taxation literature is to base the estimation on groups of close equals, defined across the range of incomes. ${ }^{21}$ Specifically, suppose we identify $N$ groups of close equals in period one, $G_{j}, j=1, \ldots, N$. For any country $k$, belonging to group $j$, we can, without loss of generality, write $y_{k}^{2}=y_{G_{j}}^{2}+e_{k}$, where $y_{G_{j}}^{2}$ denotes expected income in period two conditional on membership of group $j$ in period one and $e_{k}$ represents a zero-mean stochastic deviation from the expected income. The change in inequality can then be written as

$$
\begin{aligned}
\Delta G & =\left[\left(C_{G}^{2}-C_{1}^{2}\right)+\left(C_{2}^{2}-C_{G}^{2}\right)\right]-\left[\left(C_{1}^{1}-C_{1}^{G}\right)+\left(C_{1}^{G}-C_{1}^{2}\right)\right] \\
& =(E R+S R)-(E B C+S B C)
\end{aligned}
$$

where $C_{j}^{i}$ is the concentration coefficient of incomes $i$ with respect to $j$ rankings. For example, $C_{2}^{2}$ is the concentration coefficient of final-period income when ranked according to final income (or equivalently the final-period Gini coefficient), while $C_{G}^{1}$ is the concentration curve of initial incomes when ranked on the basis of expected group means in the final period. When ranking countries on the basis of expected group means we order first by expected group mean and then within each group by initial income.

The terms inside the first square brackets in (A1) decompose our original re-ranking term, $R$, into a systematic or expected re-ranking component $(E R)$ that arises due to nonlinearities in the conditional mean function and a stochastic re-ranking component $(S R)$ arising due to country deviations around the growth path. Whenever the conditional mean function is monotonic, $C_{G}^{2}$ will be equal to $C_{1}^{2}, E R$ will equal zero and all the changes in our re-ranking term will reflect stochastic shocks given by $S R$.

The terms inside the second square bracket reflect our decomposition of our $\beta$-convergence term $(B C)$. The first component $(E B C)$ measures the $\beta$-convergence between initial incomes and expected final-period income, when both are weighted on the basis of rankings in the initial income distribution. It captures progression due to the systematic growth process and incorporates any nonlinearities that may exist in the process. The final term $(S B C)$ captures $\beta$-convergence associated with differences between expected and actual second-period incomes, again with fixed rankings. Intuitively this term captures the effect of 'within-group convergence'. If all countries received their expected incomes in the second period this term would be zero. If on the other hand initially poorer countries benefited disproportionately from the observed shocks then $S B C$ would be positive, leading to a fall in inequality. ${ }^{22} S B C$ is negative and inequality rises if richer countries benefit most from the shocks.

\footnotetext{
${ }^{21}$ See van de Ven et al. (2001) for a discussion on how you might define the close-equals groups optimally in terms of class width.

${ }^{22}$ This decomposition is best considered when there are no exact equals in the initial income distribution. If the groups are selected on the basis of exact equals then it is difficult to know how to order individuals within a group. One could consider defining the concentration curve as the average curve across all possible orderings. This is equivalent to assigning $y_{G}$ to each member of the group so that the ordering does not matter (see, for example, Schechtman and Yitzhaki, 2003). If this is the approach adopted then by construction $C_{1}^{2}$ will equal $C_{1}^{G}$ and the $H$ term in our extended decomposition will equal zero. In the absence of exact equals, however, these need not be equal and the $S B C$ term retains the interpretation provided above.
} 
Implementation of this extended decomposition requires a precise estimate of the conditional mean function for groups of close equals that can capture potential nonlinearities in the growth process. Unfortunately, given the relatively small number of observations in our samples, obtaining reliable, smooth estimates proves to be difficult. Therefore, we do not attempt to distinguish between the systematic and random components in this paper and focus instead on the simpler decomposition given by equation (3).

\section{REFERENCES}

Barro, R. and Sala-Martin, X. (1992). 'Convergence', Journal of Political Economy, Vol. 100, No. 2, pp. 223-251.

Barro, R. and Sala-i-Martin, X. (1995). Economic Growth, New York, McGraw-Hill. Boyle, G. and McCarthy, T. (1997). 'A Simple Measure of $\beta$-Convergence', Oxford Bulletin of Economics and Statistics, Vol. 59, No. 2, pp. 257-264.

Canova, P. (2004). 'Testing for Convergence Clubs in Income per Capita: a Predictive Density Approach', International Economic Review, Vol. 45, No. 1, pp. 49-77.

Cowell, F. A. (2000). 'Measurement of Inequality', in A. B. Atkinson and F. Bourguignon (eds), Handbook of Income Distribution, Amsterdam, North Holland, pp. 87-166.

Dardanoni, V. and Lambert, P. (2002). 'Progressivity Comparisons', Journal of Public Economics, Vol. 86, pp. 99-122.

Donaldson, D. and Weymark, J. (1980). 'A Single-parameter Gerneralization of the Gini Indices of Inequality', Journal of Economic Theory, Vol. 22, pp. 67-86.

Duclos, J.-Y., Jalbert, V. and Araar, A. (2003). 'Classical Horizontal Inequity and Reranking: an Integrating Approach', CIRPEE Working Paper 03-06.

Esteban, J. M. and Ray, D. (1994). 'On the Measurement of Polarization', Econometrica, Vol. 62, No. 4, pp. 819-851.

Esteban, J. M., Duclos, J.-Y. and Ray, D. (2004). 'Polarization: Concepts, Measurement, Estimation', Econometrica, Vol. 72, No. 6, pp. 1737-1772.

Fiaschi, D. and Lavezzi, A. M. (2003). 'Distribution Dynamics and Nonlinear Growth', Journal of Economic Growth, Vol. 8, pp. 379-401.

Friedman, M. (1992). 'Do Old Fallacies Ever Die?', Journal of Economic Literature, Vol. 30, No. 4, pp. 2129-2132.

de la Fuente, A. (1997). 'The Empirics of Growth and Convergence: a Selective Review', Journal of Economic Dynamics and Control, Vol. 21, pp. 23-73.

de la Fuente, A. (2003). 'Convergence Equations and Income Dynamics: the Sources of OECD Convergence, 1970-1995', Economica, Vol. 70, pp. 655-671.

Gastwirth, J. L. (1971). 'A General Definition of the Lorenz curve', Econometrica, Vol. 39, pp. 1037-1039.

de Groot, H., Abreu, M. and Florax, R. (2005). 'A Meta-analysis of Betaconvergence: the Legendary 2\%', Journal of Economic Surveys, Vol. 19, No. 3, pp. 389-420.

Hart, P. (1995). 'Galtonian Regression across Countries and the Convergence of Productivity', Oxford Bulletin of Economics and Statistics, Vol. 57, No. 3, pp. $287-293$.

Islam, N. (2003). 'What Have We Learnt from the Convergence Debate', Journal of Economic Surveys, Vol. 17, pp. 309-362.

Jenkins, S. P. (1991). 'The Measurement of Income Inequality', in L. Osberg (ed.), Economic Inequality and Poverty: International Perspectives, New York, M.E. Sharpe, pp. 3-38. 
Jenkins, S. and Van Kerm, P. (2006). 'Trends in Income Inequality, Pro-poor Income Growth and Income Mobility', Oxford Economic Papers, Vol. 58, No. 3, pp. 531-548.

Jones, C. (1997). 'On the Evolution of the World Income Distribution', Journal of Economic Perspectives, Vol. 11, No. 3, pp. 19-36.

Kakwani, N. (1977). 'Measurement of Tax Progressivity: an International Comparison', The Economic Journal, Vol. 87, pp. 71-80.

Kalaitzidakis, P., Mamuneas, T. and Stengos, T. (2000). 'A Non-linear Sensitivity Analysis of Cross-country Regressions', Canadian Journal of Economics, Vol. 33, pp. 604-617.

Lambert, P. (1993). The Distribution and Redistribution of Income, Manchester, Manchester University Press.

Lerman, R. and Yitzhaki, S. (1995). 'Changing Ranks and the Impact of Taxes on Transfers', National Tax Journal, Vol. 48, No. 1, pp. 45-59.

Maasoumi, A., Racine, J. and Stengos, T. (2007). 'Growth and Convergence: a Profile of Distribution Dynamics and Mobility', Journal of Econometrics, Vol. 136, No. 2, pp. 483-508.

O’Neill, D. (1996). 'Education and Income Growth: Implications for Cross-country Inequality', Journal of Political Economy, Vol. 103, No. 6, pp. 1289-1301.

Phillips, P. and Sul, D. (2003). 'The Elusive Empirical Shadow of Growth Convergence', Cowles Foundation Discussion Paper 1398.

Quah, D. (1993). 'Galton's Fallacy and Tests of the Convergence Hypothesis', Scandinavian Journal of Economics, Vol. 95, pp. 427-443.

Quah, D. (1996). 'Empirics for Economic Growth and Convergence', European Economic Review, Vol. 40, pp. 1353-1375.

Sala-i-Martin, X. (1996a). 'The Classical Approach to Convergence Analysis', Economic Journal, Vol. 106, pp. 1019-1036.

Sala-i-Martin, X. (1996b). 'Regional Cohesion: Evidence and Theories of Regional Growth and Convergence', European Economic Review, Vol. 40, pp. 1325-1352.

Schechtman, E. and Yitzhaki, S. (2003). 'A Family of Correlation Coefficients Based on the Extended Gini Index', Journal of Economic Inequality, Vol. 1, No. 2, pp. $129-146$.

Sugimoto, Y. (2006). 'Inequality, Growth and Overtaking', Macroeconomic Dynamics, Vol. 10, No. 5, pp. 625-651.

Urban, I. and Lambert, P. (2005). 'Redistribution, Horizontal Inequity and Reranking: How to Measure Them Properly', University of Oregon. http:// economics.uoregon.edu/papers/UO-2005-12_Lambert_Redistribution.pdf

van de Ven, J., Creedy, J. and Lambert, P. (2001). 'Close Equals and Calculation of the Vertical, Horizontal and Reranking Effects of Taxation', Oxford Bulletin of Economics and Statistics, Vol. 63, pp. 381-394.

Wodon, Q. and Yitzhaki, S. (2005). 'Growth and Convergence: a Social Welfare Framework', Review of Income and Wealth, Vol. 51, No. 3, pp. 443-454.

Yitzhaki, S. (1983). 'On an Extension of the Gini Inequality Index', International Economic Review, Vol. 24, pp. 617-628. 